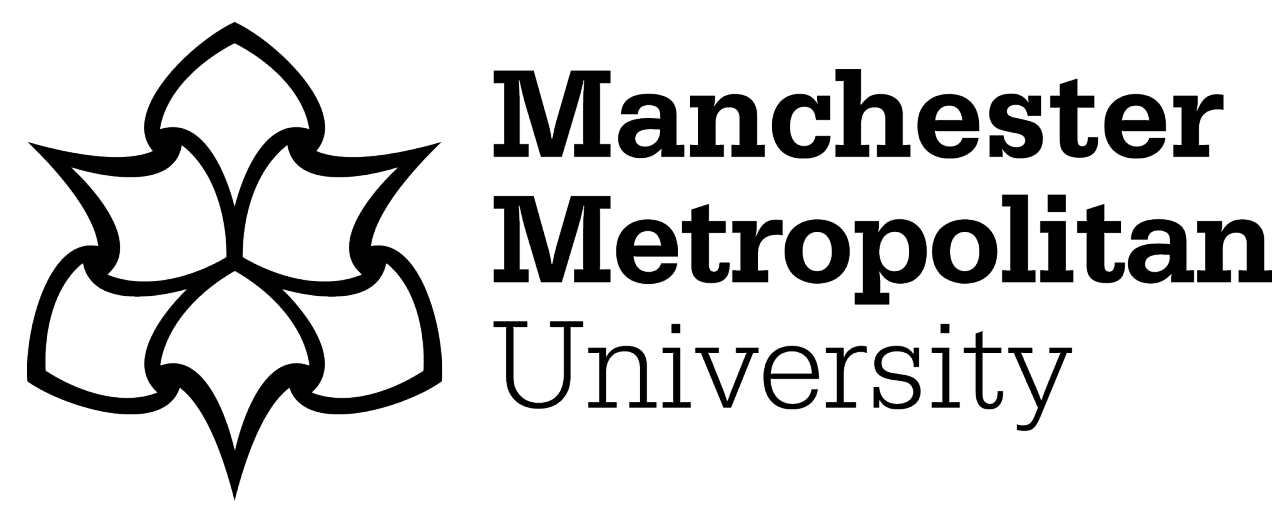

Ahmed, A, Johnson, F, Walton, G ORCID logoORCID: https://orcid.org/00000003-4251-2891 and Bayounis, S (2020) A phenomenographic approach to the effect of emotions on the information behaviour of doctoral students: A narrative inquiry. In: iConference, 23 March 2020 - 26 March 2020, University of Boras, Sweden Virtual Conference.

Downloaded from: https://e-space.mmu.ac.uk/625862/

DOI: https://doi.org/10.1007/978-3-030-43687-2_73

Please cite the published version 


\title{
A phenomenographic approach to the effect of emotions on the information behaviour of doctoral students: A narrative inquiry
}

\author{
Amira Ahmed ${ }^{10000-0003-4074-4808]}$, Frances Johnson ${ }^{1}$,Geoff Walton ${ }^{1}$, Sumayah Bayounis ${ }^{1}$ \\ ${ }^{1}$ Department of Languages, Information \& Communication, Manchester Metropolitan iSchool, \\ Manchester Metropolitan University, Manchester, UK \\ amira.ahmed@stu.mmu.ac.uk
}

\begin{abstract}
This article is to examine how emotions affect the doctoral student's journey by analyzing diverse aspects of the information behaviour that emerged from their narratives through a phenomenographic perspective. Narratives are a rational way of communication that focuses on how people perceive different phenomena regarding themselves, their inner thoughts, their states of mind, and how it affects their lifeworld's. This phenomenographic study employs interview data from 36 doctoral students. The data collected from the narratives were studied drawing from the variation theory and iterative data analysis resulted in categories of doctoral student experiences and their emotional journey. The holistic phase of the thematic analysis revealed a relatively balanced interplay of positive and negative emotions. The rich data obtained in the phenomenographic approach exposed significant links between participants' heightened emotions in five common themes during looking for information, their interactions with key individuals (supervisors and peer) and situations in their doctoral lives. Whilst this paper focuses on the approach taken to explore the narratives, recommendations are made based on the findings and to further explore the information-seeking behaviour patterns of doctoral students.
\end{abstract}

Keywords: Doctoral Students, Phenomenography, Emotions, Information Behavior.

\section{Introduction}

This research explores the lived emotional information-seeking experiences of doctoral students. In so doing, it will provide a clearer understanding of how these doctoral students' past histories and current commitments may impact the affective, cognitive, and physical elements of their experience of doctoral research. The doctoral study involves numerous challenges. These range from the everyday pressures associated with living on a reduced income to the demanding task of constructing a scholarly identity in the research world. Consequently, many doctoral students experience what has been described as a 'rollercoaster of confidence and emotions' $[1,2]$. There is evidence that doctoral students conceal their emotions $[3,4]$ and perhaps there is fear that discussing 
students feelings might morph into concern for therapeutic rather than pedagogic [5] yet 'the emotional aspects of research practice and the management of emotions are deeply embedded in being a successful doctoral student'[6]. Information scholars such as [6-8] argue that the stress and negative emotions sparked by learning a new and occasionally counter-intuitive skill may be an inevitable aspect of the information-seeking process. However, some, [9], sees students' experiences of emotional barriers during the information search process as a sign that a student is genuinely transcending his or her comfort zone of knowledge, and gaining a deeper understanding of a topic. Despite the shreds of evidence and various Information Seeking Process (ISP) models, few works have been carried out to investigate this aspect of emotional behaviour in doctoral student's study to gain insight into the emotions they faced during their research career and how various sources of information influence it.

This paper explores the emotion-infused experiences of thirty-six international and local doctoral candidates studying in the United Kingdom. The data is collected in the form of interviews conducted over a one-year period. Based on phenomenographic study, a very 'open' view of this phenomenon has been the starting point of this research, and the overall thrust is that of a process of discovery rather than a search for predetermined categories. The results revealed through the participants' narratives indicate a relatively balanced interplay of positive and negative emotions. The rich data obtained in the phenomenographic approach uncovered significant relations between participants' heightened emotions and their interactions with key individuals such as supervisors and research peers and circumstances in their doctoral lives. The paper first analyses relevant investigations into the previous studies of information-seeking behaviour and emotions before outlining the study's theoretical framework, then it describes the study's research design and methodology — next, the participants' accounts of the emotion's episodes. The final section considers the discussion and conclusion. The focus of the paper is to describe the phenomenographic approach taken and the insights obtained from the participants' narratives of their emotional incidents experienced during their doctoral study.

\section{Emotions, Information Behavior \& Doctoral Students}

Emotions are fundamentally implicated in all human behaviour. They shape perceptions, influence thinking, affect the ability to share knowledge and motivate action [10]. Emotions provide doctoral students with motivational energy to persist until graduation [11]. However, they can also inhibit thinking. For example, anxiety has been shown to interfere with doctoral candidates' ability to write [12]. Emotions can also help in achieving desired outcomes, as demonstrated in [13] account of doctoral students' experiences dealing with stress. Furthermore, studies have been investigated to evaluate the effect of emotions, specifically on users' information-seeking behaviour. According to [14], emotional factors affect search strategies and performance, search results, motivation, and satisfaction. In [15], they investigated the cognitive and affective aspects of information-seeking behaviour among novice users. The study found that need for confirmation, hesitation, surprise, and fear affected the strategies that the users applied 
in the search process.[16] describes different information behaviour according to anxiety or relaxation, and need for control, and under/oversupply of information among other factors. According to [17], factors such as course, age, level, native language, and religion have a substantial effect on the information-seeking behaviour of college students.

Finally, different researchers have focused on diverse elements of information-seeking behaviour among university students. Previous studies have delved the differences in the information-seeking behaviour of local and international students (e.g. [18-21]. [22] compared the information-seeking behaviour of local and international students at the University of Illinois. While focusing on professionals, [23] offer insights regarding the information-seeking behaviour expected of academics. This study draws on the above studies that information seeking has an affective dimension, and that doctoral student will seek information to support their study from various sources, such as from the literature, other researchers, their peers and supervisors.

\section{$3 \quad$ Methodology}

This paper acknowledges an important aspect on how doctoral students perceive emotion and poses the following research question:

- What is the effect of emotions on the information behaviour of doctoral students' research journey?

To answer this, a phenomenographic approach was chosen based on the variation theory $[24,25]$.

\subsection{Study Design and Approach}

The objective of phenomenography is to describe qualitatively the various ways in which individuals conceive phenomena in their unique worlds [26]. The investigators aim to classify conceptions of a phenomenon of interest as accurately as possible and refrain from interjecting their preconceived concepts. Analysis within the phenomenographic approach is discussed in the literature [27-29]; however, there is, as yet, no clear one 'best' method of phenomenographic analysis. The objective, however, is largely to describe the data in the form of qualitative categories, often referred to as the 'outcome space', looking to find similarities or differences. Usually, the categories of description are related to one another in some manner, often in a hierarchical manner. In addition, our decision to use a person-centred approach as opposed to a segmentcentered approach was because our research question was aimed at investigating specifically the variation in how doctoral students lived experiences influenced by emotions. 


\subsection{Setting, Participants and Their Recruitment}

One of the essential elements when designing a phenomenographic study is the selection of the participants. Since the purpose of phenomenography is to uncover the qualitatively different ways that a specific phenomenon is understood, the participants should be selected to obtain the maximum possible diversity. This implies the use of a purposeful sampling method [30]. To obtain the maximum possible variations, participants selection was based on the demographic attributes of gender, age, race, nationality (domestic/international), intended doctoral major, family orientation and overall personalities. The students come from a diversity of majors but were screened to ensure that they had a recent researching experience to be included in the study. The participants were recruited with all the approachable mediums and were introduced to the study individually, followed by filling consent forms. The demographic variations of participant samples are shown in (Table 1).

Table 1. Demographic variation in participant sample

\begin{tabular}{|l|l|r|}
\hline \multicolumn{1}{|c|}{ Categories } & \multicolumn{1}{|c|}{ Groups } & Counts \\
\hline Gender & Female & 21 \\
Age & Male & 15 \\
& $18-28$ & 8 \\
& $29-38$ & 15 \\
& $39-48$ & 10 \\
Nationality & $58+$ & 3 \\
& Domestic & 11 \\
Enrolled Course & International & 25 \\
(PhD) & & \\
& Arts and Humanities & 13 \\
& Computer Science & 10 \\
& Science \& Technology & 4 \\
& Health \& Social Care & 3 \\
& Business \&Economics & 2 \\
& Other & 1 \\
& Married & 6 \\
& Married with kids & 15 \\
& Single & 6 \\
& Single with kids & 3 \\
& Separated & 2 \\
& Engaged & 1 \\
& Other & 0 \\
& & \\
& &
\end{tabular}

\subsection{Data Gathering}

This article draws on the transcripts of 36 hour-long interviews conducted between a year-long period and a small number of email exchanges aimed at clarifying issues identified during the transcription process. The researcher conducted interviews with each participant on their campus. The fact that the researcher was also a doctoral student who helped establish rapport with the participants, despite differences in age and background. 


\subsection{Explication of the Findings}

In a phenomenographic approach, data are explained rather than analyzed. The six steps include bracketing; defining emotional aspects; clustering lived experiences of interviews lifeworld and defining a relation for each emotion episodes; summarizing each interview/discussion and validating it and, where necessary, modifying it (results); and extracting general and unique themes (discussion) [31]. Bracketing refers to containing the researchers' views and preconceptions, so they do not influence the interview/ discussion of the findings. The investigator repeatedly listened to the audio recordings to familiarize with the contributors' words and develop a holistic sense. The tapes were transcribed and read and reread multiple times to develop a holistic sense harmoniously. Significant statements related to the study goal were marked. The emotional aspects of the phenomenon of doctoral students during their study were identified.

\section{Emotion Incidents in Doctoral Narratives}

This section reports emotion incidents that emerged in the participants' (subjects') narratives while conducting open-ended interviews regarding their information-seeking behaviour. The findings reveal seven categories, which directly affected the emotional state of doctoral students lived experiences while researching for information Some individual's variance themes were also identified which are depended on individual's demographics (Table 2).

Table 2. Common themes and emotional episodes

\begin{tabular}{|c|c|c|c|c|c|}
\hline \multirow[b]{2}{*}{$\begin{array}{c}\text { DIMENSIONS } \\
\text { OF } \\
\text { VARIANCE }\end{array}$} & \multicolumn{5}{|c|}{ COMMON THEMES } \\
\hline & $\begin{array}{l}\text { Language } \\
\text { Barriers }\end{array}$ & $\begin{array}{l}\text { Personal } \\
\text { Problems }\end{array}$ & \begin{tabular}{|l} 
Self \\
Motiva- \\
tion \\
Passion \\
\end{tabular} & $\begin{array}{l}\text { Profes- } \\
\text { sional } \\
\text { Communi- } \\
\text { ties }\end{array}$ & $\begin{array}{l}\text { Supervisor } \\
\text { Relation- } \\
\text { ship }\end{array}$ \\
\hline \multirow[t]{2}{*}{$\begin{array}{l}\text { Family Status } \\
\text { Health Issues } \\
\text { Finance } \\
\text { Gender } \\
\text { Nationality } \\
\text { Past Experi- } \\
\text { ences }\end{array}$} & \multicolumn{5}{|c|}{ 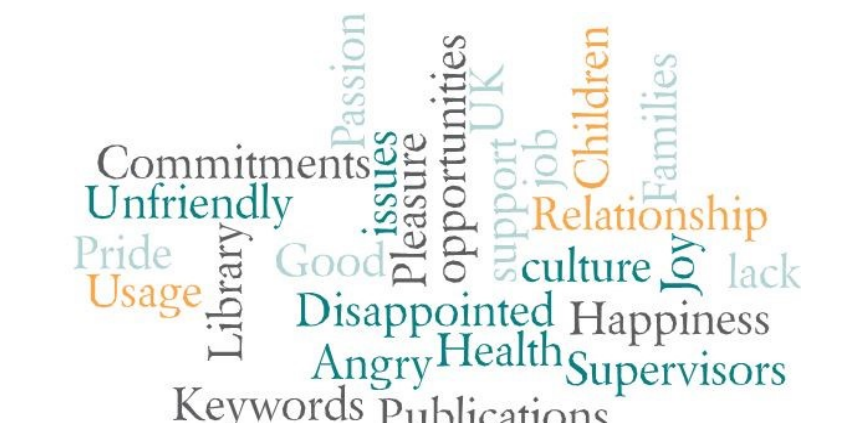 } \\
\hline & & EMC & TIONAL & PISODES & \\
\hline
\end{tabular}




\subsection{Language Barrier}

Almost all of the doctoral students indicated one common theme, writing and given the salience of review in writing activities; this is hardly surprising. The trials associated with writing in English generated mainly strong emotions:

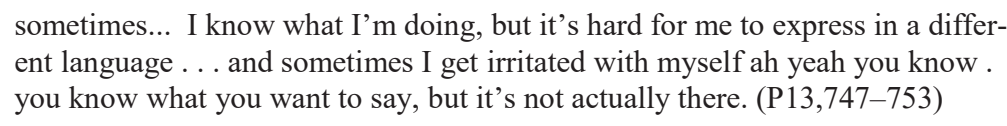

In addition to triggering anger, anxiety and frustration, participants(P28,P24,P12) whined that writing was time-consuming and took time away from other activities. Given these challenges, participants expressed joy and pride when their scripts were accepted for publication. All international students did mention that looking for the right keyword to research for information is troublesome for them and results in high anxiety and frustration.

I feel reluctant to use new keywords.....during research, I found new keywords...., which I never used before, so it worries me, and felt...uhm.... I am incapable of using library services... Sometimes I do feel I did not know how to research umm.....I cannot continue my $\mathrm{PhD}$ (P4,117-120).

\subsection{Personal Problems}

Doctoral studies have numerous challenges and the most common theme which generated strong emotions are a personal problem. Every individual has their own circumstances which directly affect their doctoral journey, especially not meeting deadlines, and participants indicated finance, health and family commitments. P19 reported that she and her husband had started discussing job prospects:

P: We started discussing about that [the future]. Yeah, for him I think, I don't concern about him at all. And ah for myself, I am sceptical.

R: Why?

P: Ah, ah about what kind of job I can find and ah I have to get a good publication to get a good... academic career. (P19, 1556-1562)

Her anxiety about finding an academic post was exacerbated by knowing that her student visa would expire shortly after she submitted her thesis. If she was to remain in the UK, she needs to find a job offer.

\subsection{Self Motivation/Passion}

Self Motivation or Passion emerged as a critical theme that affected doctoral students in very different ways. Although P17, P16 and P27 spent large parts of interview eagerly sharing what they had learned about her two different methodologies, P9 and P22 could barely remember either of her data collection techniques and didn't talk much about one. P27 repeatedly stated that she was 'passionate 'about learning new things 
and sharing them with her professors, friends and future clients. However, P22 overriding passion seemed to be directed toward completing assessments (which she described as 'obstacles 'and 'blocks') that required information-seeking through brute force. While neither motivation is better than the other, their different passions may have led to different approaches to information seeking.

\subsection{Professional Communities}

Almost three-quarter of international candidates referred to feelings concerning interactions with members of their different communities which caused the information searching. Their experiences within their departments were consistently negative, while their interactions in their respective communities were (in all but one case) extremely positive.

P7 complained about her department's unfriendly culture and felt 'very, very troubled' (741) at what she perceived as a lack of welcome and orientation when she first arrived. P18, P24, P30 also regretted the absence of peers with whom to discuss ideas. This lack of departmental community sent a powerful (unintended?) message that scholarly research is a solitary affair. In contrast, participants' interactions with their disciplinary communities at conferences and in the publication process were highly positive. P18's account of attending a 'very prestigious' international conference in Europe conveys his pleasure and pride:

that was really interesting because ... it gave me really good feedback ... during the break, people were coming to me ... and they were telling me they are impressed about what I am doing ... (P18, 271-280).

By participating in this conference, $\mathrm{P} 18$ experienced the satisfaction of being recognized as a researcher by others in his disciplinary community. P24 contacted two international experts in his field about a paper he was writing and was delighted to receive positive feedback on the work he was doing. In both cases, this emotional boost was converted into enhanced confidence and motivation.

\subsection{Supervisor Relationships}

The last aspect of the participants' experiences which has so many emotions involved was their interactions with their supervisors. Most of the participants' comments about their supervisors were positive, with individuals acknowledging their efficiency, support, feedback and friendly manner. P34 explained that his supervisors' trust in his ability had given him the confidence to begin writing:

P: when ... you are a person from an environment that does not really value publication as it is here, and then you come to this place -

$\mathrm{R}$ : - to compete on an even footing -

P: Yes ... I was thrilled that my supervisors yeah they trust me, tried to motivate me - 'Yes you can, you have experienced' and ... when we discuss content-based knowledge,... (P34) 
On the other hand, P18 considered the role his supervisor assigned him is unsuitable and face-threatening. However, conscious of the power dynamics at work, he chose not to counterattack. Instead, he lowered his sights and chose to focus on 'just finishing' the $\mathrm{PhD}$ :

I guess there was a lot of drive, but ... you just reach a point where you don't really care anymore what occurs, all you want to do is just ... try to see if you can have the results and try to finish. (P18, 902-913)

When asked to explain, the interesting way P18 paraphrased his supervisor's appraisal of his work revealed his suppressed anger:

P: at the beginning well I could write stuff and ... he doesn't understand it so 'it's bullshit... .it's rubbish'. Well, I would like -

R: Would he actually use that word with you?

P: Of course, he would say it doesn't make sense to him. (P18, 918-923)

\section{$5 \quad$ Discussion \& Conclusion}

Emotions play an intricate role in doctoral experiences. This paper focuses on the phenomenographic approach taken to explore the participants' narratives and to identify the categories (or themes) that describe their emotive incidents, and that was chosen based on variation theory seeking similarities and differences across the participants' experience within each incident.

Language barriers, personal problems, self-motivation/passion, professional communities and supervisor relationship all play a part in doctoral narratives. Writing English for those whose first language is not English experienced particularly strong emotions. Personal problems also generated concern, especially with respect to future job prospects. Self-motivation/passion was a core driver and talking about professional communities was emotive and which appeared to influence action. Perceived lack of time affected the students emotionally as did supervisor relationships, especially concerning the influence the supervisor can have.

Hence, it can be seen that emotions underlie all of these themes and it is anticipated that the approach taken will allow us to further explore how the emotions within these incidents have influenced thinking and motivated action in the doctoral student journey from start to finish. The depth of insight afforded results in a model of the emotional journey and one which acknowledges how emotion may be influenced (especially by information resources and services encountered) and managed to inspire, guide and enhance the doctoral student and their research trajectory. In doing so, the doctoral journey will not only become more effective but also more enjoyable for both supervisors and students alike. 


\section{References}

1. Ezzy, D.: Theorizing narrative identity: Symbolic interactionism and hermeneutics. Sociological quarterly, 39(2), pp.239-252 (1998).

2. Schutz, P.A., Hong, J.Y., Cross, D.I., \& Osbon, J.N.: Reflections on investigating emotion in educational activity settings. Educational Psychology Review, 18(4), 343-360 (2006).

3. Herman, C.: Emotions and being a doctoral student. In P. Thomson \& M. Walker (Eds.), Routledge doctoral student's companion: Getting to grips with research in education and the social sciences (pp. 283-294). London and New York: Routledge (2010).

4. Manathunga, C.: Early warning signs in postgraduate research education: A different approach to ensuring timely completions. Teaching in Higher Education, 10(2), 219-233 (2005).

5. Beard, C., Smith, K., and Clegg, S.: Acknowledging the Affective in Higher Education, British Educational Research Journal, 33, (2), April, pp. 235-252 (2007).

6. Thomson, P., \& Walker, M.: Routledge doctoral student's companion: Getting to grips with research in education and the social sciences. London and New York: Routledge (Eds.) (2010).

7. Kuhlthau, C.C.: Seeking meaning: a process approach to library and information services. 2nd. ed. Westport, CTLibraries Unlimited (2004).

8. Nahl, D. and Bilal, D.: Information and emotion: The emergent affective paradigm in information behaviour research and theory. Medford, N.J: Information Today. (2007).

9. Julien, H. and Genuis, S.K.: Emotional labour in librarians' instructional work. Journal of Documentation 65(6), pp. 926-37. Available at: http://dx.doi.org/10.1108/00220410910998924 (2009).

10. Lupton, D.: The emotional self: A sociocultural exploration. Thousand Oaks, CA: Sage (1998).

11. McCormack, C.: Postgraduate research students' experience: It's all about balancing living. In M. Tight, K.H. Mok, J. Huisman, \& C.C. Morphew (Eds.), The Routledge international handbook of higher education (pp. 181-193). New York and London: Routledge (2009).

12. Castello, M., Inesta, A., \& Monereo, C.: Towards self-regulated academic writing: An exploratory study with graduate students in a situated learning environment. Electronic

13. Journal of Research in Educational Psychology, 7(3), 1107-1130 (2009).

14. Hopwood, N., \& Stocks, C.: Teaching development for doctoral students: What can we learn from activity theory? International Journal for Academic Development, 13(3), 175-186 (2008).

15. Lopatovska, I.: Emotional aspects of the online information retrieval process. PhD. Rutgers University-Graduate School-New Brunswick (2009).

16. Nahl, D., and Tenopir, C.: Affective and cognitive searching behaviour of novice end-users of a full-text database.' Journal of the American Society for Information Science, 47(4) pp. 276-286 (1996).

17. Heinstrom, J.: Fast surfing, broad scanning and deep diving: The influence of personality and study approach on students' information-seeking behaviour.' Journal of documentation, 61(2) pp. 228-247 (2005).

18. Devi, S. T., and Dlamini, N. N.: Information needs and seeking behaviour of Agricultural students at the University of Swaziland: A case study.' International Journal of Digital Library Services, 4(2) pp.1-15 (2013).

19. Abdoulay, K.: Information seeking behaviour of African students in Malaysia: a research study Information Development, 18(3) pp. 191-195 (2002). 
20. Dalglish, C. L., and Chan, A. O.: Expectations and reality-international student reflections on studying in Australia.' Australian International Education Conference (2005).

21. Deumert, A., Marginson, S., Nyland, C., Ramia, G., and Sawir, E. 'The social and economic security of international students in Australia: Study of 202 student cases (Summary report).' Melbourne: Monash University (2005).

22. Liu, M. and Redfern, B.: Information seeking behaviour of Multicultural students: A case study at San Jose State University.' College and Research Libraries, 58(4) pp. 348-354 (1997).

23. Song, Y.S.: A comparative study on information-seeking behaviours of domestic and international business students.' Research Strategies, 20(1/2) pp. 23- 34 (2005).

24. Shafique, F., and Mahmood, K.: Variable Affecting the Information Needs and Seeking Behaviour of Educational Administrators: A Review.' Pakistan Journal of Library \& Information Science, (14) pp. 26-32 (2013).

25. F. Marton, "Phenomenography — describing conceptions of the world around us," Instructional Science, vol. 10, no. 2, pp. 177-200, (1981).

26. C. Yates, H. L. Partridge, and C. S. Bruce, "Exploring information experiences through phenomenography," Library and Information Research, vol. 36, no. 112, pp. 96-119, (2012).

27. Reed, B.: Phenomenography As a Way to Research the Understanding by Students of Technical Concepts, Nucleo de Pesquisa em Tecnologia da Arquitetura eUrbanismo (NUTAU): Technological Innovation and Sustainability, S ao Paulo, Brazil (2006).

28. Svensson, L.: Theoretical foundations of phenomenography", Higher Education Research \& Development, vol. 16, no. 2, pp. 159-171 (1997).

29. Ashworth, P. \& Lucas, U.: What is the 'World' of Phenomenography?" Scandinavian Journal of Educational Research, vol. 42, no. 4, pp. 415-431 (1998).

30. Larsson, J. \& Holmstrom, I.: Phenomenographic or phenomenological analysis: does it matter? Examples from a study on anaesthesiologists' work", International Journal of Qualitative Studies on Health and Well-Being, vol. 2, no. 1, pp. 55-64 (2007).

31. Bowden, J. A., \& Green, P. (Eds.). Doing developmental phenomenography.: RMIT University Press (2005).

32. Åkerlind, G., Bowden, J. A., \& Green, P.: Learning to do phenomenography: A reflective discussion. In J. Bowden \& P. Green (Eds.), Doing developmental phenomenography (pp. 74-100). Melbourne, Australia: RMIT University Press (2005). 